\title{
PENGARUH EDUKASI TENTANG PERAWATAN MUKOSITIS ORAL TERHADAP PENGETAHUAN KELUARGA PASIEN YANG MEMPUNYAI ANAK DENGAN KANKER DI YAYASAN AMARYLLIS KIRANA TANGERANG
}

\author{
Naziyah $^{1}$, Susanti Widiastuti ${ }^{2}$
}

${ }^{1}$ Dosen Program studi keperawatan Universitas Nasional Email : naziyah.ozzy@gmail.com

${ }^{2}$ Dosen Program studi keperawatan Universitas Nasional Email : susanti_widiastuti76@yahoo.com

\section{ABSTRACT : THE EFFECT OF EDUCATION OF MUCOSITIS ORAL TREATMENT ON KNOWLEDGE OF PATIENTS FAMILY WHO HAVE CHILDREN WITH CANCER IN AMARYLLIS KIRANA FOUNDATION TANGERANG}

Background : The occurrence of grade 3-4 oral mucositis is found in about $85 \%$ of cancer patients. The high incidence of oral mucositis will hinder the process of treatment and recovery of children aged 6-12 years with cancer. Efforts to overcome the problems that arise in children are focused in Family knowledge about the treatment of oral mucositis in children with cancer means that action can be given by providing education.

Purpose: To determine the effect of education about the treatment of oral mucositis on the patients family knowledge who have children with cancer.

Methods: The research design used is Quasi Experimental using one group pre-post test design. The sample is 34 respondents using purposive sampling technique. The research instrument used the Pearson Corellation validity test with the results of $r$ count $>r$ table (14 respondents) $=0,532$ and the Cronbach Coefficient Alpha reluability test value 0,912.

Results: The Average value og knowledge of the family of patients who have children with cancer before education is 10,5882 and after education is 19,0294 an increase of 8,4412 . The results of the paired T-test statistical analysis obtained $\mathrm{p}$-value of $0,000<a(0,05)$.

Conclusion : There is an effect of the education of oral mucositis care on knowledge of patients family who have children with cancer. It is recommended that the on patients family apply it in the home environment towards the maintence and improvement of oral mucositis care ini children with cancer.

Keyword : Education, treatment of oral mucositis, family centered care.

Naziyah $^{1}$, Susanti Widiastuti ${ }^{2}$

${ }^{1}$ Dosen Program studi keperawatan Universitas Nasional. Email : naziyah.ozzy@gmail.com

${ }^{2}$ Dosen Program studi keperawatan Universitas Nasional. Email : susanti_widiastuti76@yahoo.com 


\section{INTISARI : PENGARUH EDUKASI TENTANG PERAWATAN MUKOSITIS ORAL TERHADAP PENGETAHUAN KELUARGA PASIEN YANG MEMPUNYAI ANAK DENGAN KANKER DI YAYASAN AMARYLLIS KIRANA TANGERANG}

Pendahuluan: Kejadian mukositis oral grade 3-4 ditemukan pada sekitar $85 \%$ pasien kanker. Tingginya angka kejadian mukositis oral akan menghambat proses perawatan dan kesembuhan anak usia 6-12 tahun dengan kanker. Upaya mengatasi masalah yang timbul pada anak difokuskan pada intervensi keperawatan Family Centered Care. Namun, kurangnya pengetahuan keluarga tentang perawatan mukositis oral pada anak dengan kanker maka tindakan yang dapat diberikan dengan cara pemberian edukasi.

Tujuan : Untuk mengetahui pengaruh edukasi tentang perawatan mukositis oral terhadap keluarga pasien yang mempunyai anak dengan kanker

Metode: Desain penelitian yang digunakan adalah quasi experimental menggunakan rancangan one group pre-post test design. Sampel berjumlah 34 responden mengggunakan teknik pengambilan sampel purposive sampling. Instrumen penelitian menggunakan uji validitas Korelasi Pearson dengan hasil $r$ hitung $>r$ tabel $(14$ responden $)=0,532$ dan nilai uji reliabilitas Cronbach Coefficient Alpha 0,912.

Hasil Penelitian: Nilai rata-rata pengetahuan keluarga pasien yang mempunyai anak dengan kanker sebelum dilakukan edukasi sebesar 10,5882 dan sesudah dilakukan edukasi menjadi sebesar 19,0294 terjadi peningkatan sebesar 8,4412. Hasil analisis statistik paired T-test didapatkan $\mathrm{p}$-value yaitu $0,000<a(0,05)$.

Kesimpulan dan Saran : Ada Pengaruh tentang edukasi perawatan mukositis oral terhadap keluarga pasien yang mempunyai anak dengan kanker dengan nilai $p$ value $0,000<a(0,05)$. Disarankan peran keluarga menerapkannya di lingkungan rumah terhadap pemeliharaan dan meningkatan perawatan mukositis oral pada anak dengan kanker.

Kata Kunci : edukasi, perawatan mucositis oral, family centered care.

Naziyah $^{1}$, Susanti Widiastuti ${ }^{2}$

${ }^{1}$ Dosen Program studi keperawatan Universitas Nasional. Email : naziyah.ozzy@gmail.com

${ }^{2}$ Dosen Program studi keperawatan Universitas Nasional. Email : susanti_widiastuti76@yahoo.com 


\section{PENDAHULUAN}

Menurut data International Agency for Research On Cancer (IARC) (2014) insiden kanker meningkat dari 12,7 juta kasus pada tahun 2008 menjadi 14,1 juta kasus pada tahun 2012. Di Amerika, kanker yang paling umum pada anak-anak usia 0-14 tahun adalah leukimia limfositik akut (26\%), kanker otak dan sistem saraf pusat (SSP) (21\%), Neuroblastoma (7\%), dan Lymphoma non-Hodgkin (6\%) Menurut American Cancer Society, 2014. Kanker merupakan penyakit yang ditandai dengan adanya perubahan sel normal menjadi sel abnormal yang tidak terkontrol dan dapat bermetastasis baik menginvasi jaringan terdekat maupun jaringan biologis yang jauh (Setiawan, 2015). Kasus kanker yang terjadi di Indonesia pada tahun 2013 mencapai 1,4\%.

Prevalensi kanker tertinggi yang terjadi di Indonesia terdapat di wilayah Daerah Istimewa Yogyakarta (DIY) yaitu sebesar 4,1\% pada 1000 orang, di urutan kedua yaitu Jawa Tengah sebesar 2,1\% atau sekitar 68.638 orang (Kementrian Kesehatan RI, 2015). Menurut WHO Tahun 2011 bahwa kejadian mukositis oral grade 3-4 ditemukan pada sekitar 85\% pasien kanker kepala dan leher yang menerima kemoterapi. Mukositis oral Grade 3 atau 4 terjadi pada $75 \%$ pasien yang menjalani sel induk hematopoietik transplantasi (HSCT), 50\% pada limfoma non-Hodgkin, kanker payudara, paru-paru dan kanker kolorektal. Mukositis oral adalah peradangan yang terjadi pada oral mukosa akibat terpapar agen kemoterapi atau ion radiasi ( Haris.D et. al 2007). Mukositis oral merupakan efek samping yang sangat signifikan dari terapi kanker, lesi-lesi mukositis oral dapat menyebabkan rasa nyeri odynodysphagia, dysgeusia, yang berakibat timbulnya dehidrasi dan malnutrisi karena menurunnya asupan gizi dan derajat kesehatan mulut serta meningkatkan risiko infeksi lokal dan sistemik. Mukositis oral ini dapat menyebabkan morbiditas, meningkatkan biaya perawatan, menurunkan kesehatan umum dan kualitas hidup pasien, serta dapat mengganggu terapi kanker sehingga kemoterapi atau radiasi tidak dapat dilanjutkan karena bisa mempengaruhi keselamatan penderita dan kesembuhan perjalanan penyakit penderita.

Tingginya angka kejadian mukositis oral ini akan menghambat proses perawatan anak dan kesembuhan anak itu sendiri. Upaya mengatasi masalah yang timbul pada anak difokuskan pada intervensi keperawatan dengan cara meminimalkan stressor, memaksimalkan manfaat hospitalisasi dan memberi dukungan psikologis pada anggota keluarga ( Wong, 2009). Terlebih pada anak usia 6-12 tahun dikarenakan anak usia sekolah merupakan usia dimana anak sedang aktif menggunakan otototot kasar mereka dari pada otototot halus. Dengan adanya kondisi sakit tidak memungkinkan anak untuk melakukan aktivitas motorik kasar, sehingga anak-anak tidak aktif. Selain itu, menurut Freud anak berusia 6-12 tahun berada pada tahap perkembangan fase laten. Pada fase ini anak sering bermain di luar dan mencari banyak teman untuk bermain sehingga pertumbuhan intelektual dan sosial mulai terbentuk (Riyadi,2009).

Dalam konsep Family Centered Care, keluarga dipandang sebagai

Naziyah $^{1}$, Susanti Widiastuti ${ }^{2}$

${ }^{1}$ Dosen Program studi keperawatan Universitas Nasional. Email : naziyah.ozzy@gmail.com

${ }^{2}$ Dosen Program studi keperawatan Universitas Nasional. Email : susanti_widiastuti76@yahoo.com 
unsur yang konstan sementara kehadiran profesi kesehatan fluktuaktif adalah sangat ideal jika anak dapat di dampingi selama 24 jam oleh orangtuanya (American Academy Of Pediatrics, 2003). Keluarga memiliki peran penting dalam perawatan kesehatan anggota keluarga, terutama yang sedang sakit (Friedman, 2010).

Keluarga penderita kanker diharapkan mampu secara mandiri memberikan dukungan dan perawatan yang tepat untuk membantu meningkatkan kualitas hidup penderita kanker pasca perawatan. Kemandirian keluarga berorientasi pada lima fungsi keluarga Dalam mengatasi masalah kesehatannya yaitu mampu mengenal masalah kesehatannya, mengambil keputusan tepat untuk mengatasi kesehatannya, melakukan tindakan keperawatan untuk anggota keluarga yang sakit, memodifikasi lingkungan sehingga menunjang upaya peningkatan kesehatan, serta memanfaatkan sarana pelayanan kesehatan yang ada (Depkes RI, 2006).

Kurangnya

pengetahuan membuat keluarga belum memahami perawatan mukositis oral pada anak dengan kanker. Hal tersebut berdampak pada kondisi penderita yang tidak stabil, sehingga harus kembali ke Rumah Sakit untuk menjalani perawatan (Krisnana, 2012). Faktor lingkungan yang berupa fisik (sarana dan prasarana) dan non fisik (edukasi dan informasi petugas kesehatan) merupakan faktor utama yang sangat dibutuhkan oleh keluarga dalam merawat anggota keluarga yang sakit.
Edukasi (pendidikan kesehatan) merupakan suatu bentuk intervensi atau upaya yang ditujukan kepada perilaku, agar perilaku tersebut kondusif untuk kesehatan. Dengan kata lain edukasi ialah mengupayakan agar perilaku individu, kelompok, atau masyarakat mempunyai pengaruh positif terhadap pemeliharaan dan peningkatan kesehatan (Notoatmodjo, 2014). Edukasi perawatan mukositis oral bertujuan agar penderita mampu mencegah mukositis oral menjadi lebih parah yang dapat mengalami penurunan pada kualitas hidup pasien anak dengan kanker.

Berdasarkan studi pendahuluan yang dilakukan peneliti dengan pengurus Yayasan Amarillys Kirana pada anak dengan kanker yang mejalani kemoterapi sering kali mengalami mukositis oral tetapi belum pernah diberikan edukasi mengenai perawatan mukositis oral. Hasil wawancara dengan $3 \mathrm{lbu}$ yang mempunyai anak dengan kanker mengatakan bahwa sakit pada daerah sekitar mulut dirasakan anaknya rata-rata setelah dilakukan kemoterapi hari ke-3 dan apabila anaknya mengalami luka pada daerah mulut diberikan obat penghilang rasa sakit tanpa tahu cara perawatan mulut yang baik dan benar. Dalam hal ini salah satu program dari Yayasan Amarillys Kirana sendiri adalah memberikan edukasi kepada keluarga, dukungan berupa edukasi dan informasi merupakan salah satu strategi peningkatan kemandirian keluarga dalam perawatan mukositis oral pada pasien anak dengan kanker.

Naziyah $^{1}$, Susanti Widiastuti ${ }^{2}$

${ }^{1}$ Dosen Program studi keperawatan Universitas Nasional. Email : naziyah.ozzy@gmail.com

${ }^{2}$ Dosen Program studi keperawatan Universitas Nasional. Email : susanti_widiastuti76@yahoo.com 
METODE PENELITIAN

Populasi dalam penelitian ini keluarga pasien yang mempunyai anak dengan kanker di Yayasan Amarillys Kirana Tangerang berjumlah 84 keluarga.

Rancangan penelitian yang digunakan quasi experimental dengan menggunakan rancangan one group pre-post test design yaitu penelitian yang mengungkapkan hubungan sebabakibat dengan cara melibatkan satu kelompok subjek. Kelompok subjek diobservasi sebelum dan setelah dilakukan intervensi. Pengolahan data menggunakan aplikasi SPSS versi 20.

\section{Hasil Penelitian}

Analisa Univariat

Tabel 1 Distribusi frekuensi jenis-jenis kanker pada anak di Yayasan Amarillys Kirana Tangerang.

\begin{tabular}{ccc}
\hline Jenis Kanker & Frekuensi & Persentase (\%) \\
\hline $\begin{array}{c}\text { Chronic } \\
\text { Mieoblastic } \\
\text { Leukemia(CML) } \\
\text { Limfoblastic }\end{array}$ & 1 & 2,9 \\
$\begin{array}{c}\text { Leukemia acute } \\
\text { (LLA) }\end{array}$ & 28 & 82,4 \\
$\begin{array}{c}\text { Mieloblastic } \\
\text { Leukemia Acute } \\
\text { (MLA) }\end{array}$ & 5 & 14,7 \\
\hline Jumlah & 34 & 100 \\
\hline
\end{tabular}

Berdasarkan Tabel 1 didapatkan hasil jenis kanker pada anak Chronic Mieoblastic Leukemia (CML) sebanyak 1 orang dengan persentase 2.9\%, Limfoblastic
Leukemia acute (LLA) sebanyak 28 orang dengan persentase $82.4 \%$, dan Mieloblastic Leukemia Acute (MLA) sebanyak 5 orang dengan persentase $14.7 \%$.

Tabel 2 Distribusi Frekuensi Usia Keluarga pasien yang mempunyai anak dengan kanker di Yayasan Amarillys Kirana sebelum mendapatkan Edukasi tentang perawatan mukositis oral

\begin{tabular}{ccc}
\hline Usia & Frekuensi & Persentase (\%) \\
\hline 18-27 Tahun & 3 & 8,8 \\
28-37 Tahun & 19 & 55,9 \\
38-47 Tahun & 11 & 32,4 \\
48-57 Tahun & 1 & 2,9 \\
\hline Jumlah & 34 & 100 \\
\hline
\end{tabular}

Berdasarkan Tabel 2 didapatkan hasil umur 18-27 tahun keluarga pasien yang mempunyai anak dengan kanker di Yayasan Amarillys
Kirana terbanyak umur 28-37 tahun sebanyak 19 orang dengan persentase sebesar $55,9 \%$.

Naziyah $^{1}$, Susanti Widiastuti ${ }^{2}$

${ }^{1}$ Dosen Program studi keperawatan Universitas Nasional. Email : naziyah.ozzy@gmail.com

${ }^{2}$ Dosen Program studi keperawatan Universitas Nasional. Email : susanti_widiastuti76@yahoo.com 
Tabel 3 Distribusi Frekuensi Riwayat Pendidikan Keluarga pasien yang mempunyai anak dengan kanker di Yayasan Amarillys Kirana sebelum mendapatkan Edukasi tentang perawatan mukositis oral

\begin{tabular}{ccc}
\hline Pendidikan & Frekuensi & Persentase (\%) \\
\hline SD & 19 & 55,9 \\
SMP Sederajat & 10 & 29,4 \\
SMA Sederajat & 5 & 14,7 \\
\hline Jumlah & 34 & 100 \\
\hline
\end{tabular}

Berdasarkan Tabel 3 didapatkan hasil riwayat pendidikan SD keluarga pasien yang mempunyai anak dengan kanker di Yayasan Amarillys Kirana terbanyak 19 orang dengan persentase sebesar 55,9.

Tabel 4 Distribusi Frekuensi Pekerjaan Keluarga pasien yang mempunyai anak dengan kanker di Yayasan Amarillys Kirana sebelum mendapatkan Edukasi tentang perawatan mukositis oral

\begin{tabular}{ccc}
\hline Pekerjaan & Frekuensi & $\begin{array}{c}\text { Persentase } \\
(\%)\end{array}$ \\
\hline Buruh & 9 & 26,5 \\
Ibu Rumah Tangga & 21 & 61,8 \\
Wiraswasta & 2 & 5,9 \\
Lainnya sebagai Petani & 2 & 5,9 \\
\hline Jumlah & 34 & 100 \\
\hline
\end{tabular}

Berdasarkan Tabel 4 didapatkan hasil pekerjaan keluarga pasien yang mempunyai anak dengan kanker di Yayasan Amarillys Kirana sebagai buruh sebanyak 9 orang dengan persentase sebesar $26,5 \%$, bekerja sebagai Ibu Rumah Tangga sebesar 21\%, bekerja sebagai Wiraswasta sebanyak 2 orang dengan persentase sebesar 5,9\%, dan pekerjaan lainnya sebagai petani sebanyak 19 orang dengan persentase sebesar $5,9 \%$.

Tabel 5 Distribusi Frekuensi

Pengetahuan Keluarga pasien yang mempunyai anak dengan kanker di Yayasan Amarillys Kirana sebelum dilakukan Edukasi tentang perawatan mukositis oral

\begin{tabular}{ccc}
\hline Pengetahuan & Frekuensi & Persentase $(\%)$ \\
\hline Baik & 14 & 41,2 \\
Kurang Baik & 20 & 58,8 \\
\hline Jumlah & 34 & 100 \\
\hline
\end{tabular}

Berdasarkan Tabel 5 didapatkan hasil pengetahuan keluarga pasien yang mempunyai anak dengan kanker di Yayasan Amarillys Kirana sebelum dilakukan edukasi tentang perawatan mukositis oral dengan kategori Baik sebanyak 14 orang yaitu sebesar $41,2 \%$ dan kategori kurang Baik sebanyak 20 orang yaitusebesar $58,8 \%$.

Naziyah $^{1}$, Susanti Widiastuti ${ }^{2}$

${ }^{1}$ Dosen Program studi keperawatan Universitas Nasional. Email : naziyah.ozzy@gmail.com

${ }^{2}$ Dosen Program studi keperawatan Universitas Nasional. Email : susanti_widiastuti76@yahoo.com 
Tabel 6 Distribusi Frekuensi Pengetahuan Keluarga pasien yang mempunyai anak dengan kanker di Yayasan Amarillys Kirana sesudah dilakukan Edukasi tentang perawatan mukositis oral

\begin{tabular}{ccc}
\hline Pengetahuan & Frekuensi & Persentase (\%) \\
\hline Baik & 34 & 100 \\
Kurang Baik & 0 & 0 \\
\hline Jumlah & 34 & 100 \\
\hline
\end{tabular}

Berdasarkan Tabel 6 didapatkan hasil pengetahuan keluarga pasien yang mempunyai anak dengan kanker di Yayasan Amarillys Kirana

\section{Analisis Bivariat}

Untuk memenuhi persyaratan analisa Paired t-test berupa data berdistribusi normal, sesudah dilakukan edukasi tentang perawatan mukositis oral dengan kategori Baik sebanyak 34 orang yaitu sebesar $100 \%$.

Tabel 7 Hasil Uji Normlitas Data

\begin{tabular}{lll}
\hline Variabel & $\mathrm{p}$-value & Keterangan \\
\hline Pre-Test & 0,200 & Normal \\
Post-Test & 0,122 & Normal \\
\hline
\end{tabular}

Berdasarkan Tabel 7 didapatkan hasil nilai kolmogorov-sminorv untuk pre-test diperoleh $p$-value
$(0,200)>0,05$ yang berarti distribusi skornya dinyatakan normal.

Tabel 7 Rata-Rata Pengetahuan Keluarga pasien yang mempunyai anak dengan kanker di Yayasan Amarillys Kirana sebelum dan sesudah dilakukan Edukasi tentang perawatan mukositis oral

\begin{tabular}{cccccccc}
\hline \multirow{2}{*}{ Variabel } & \multicolumn{2}{c}{ Pre-Test } & \multicolumn{2}{c}{ Post-Test } & \multirow{2}{*}{ t } & $\begin{array}{c}p- \\
\text { value }\end{array}$ \\
\cline { 2 - 5 } & $M$ & SD & $M$ & SD & & \\
\hline Pengetahuan & 10,59 & 2,15 & 19,03 & 1,85 & & $-24,76$ & 0,00 \\
\hline
\end{tabular}

Berdasarkan Tabel 8 didapatkan hasil rata-rata pengetahuan keluarga pasien yang mempunyai anak dengan kanker di Yayasan Amarillys Kirana sebelum dilakukan edukasi tentang perawatan mukositis oral sebesar 10,59 dan sesudah dilakukan edukasi tentang perawatan mukositis oral menjadi sebesar 19,03 terjadi peningkatan sebesar 8,44. Hasil analisis statistik 


\section{KESIMPULAN}

Hasil Pre-Test pengetahuan keluarga pasien yang mempunyai anak dengan kanker di Yayasan Amarillys Kirana dengan kategori kategori kurang Baik sebanyak 20 orang yaitu sebesar $58,8 \%$. Hasil Post-Test pengetahuan tentang perawatan mukositis oral terhadap keluarga pasien yang mempunyai anak dengan kanker di Yayasan Amarillys Kirana kategori "Baik" sebanyak 34 orang yaitu sebesar $100 \%$. Nilai rata-rata yaitu sebesar 19,0294. Nilai Rata-rata pengetahuan keluarga pasien yang mempunyai anak dengan kanker di Yayasan Amarillys Kirana sebelum dilakukan Edukasi tentang perawatan mukositis oral sebesar 10,5882 dan sesudah dilakukan

\section{DAFTAR PUSTAKA}

Adityaningrum, A. N. (2019). "Pengaruh Edukasi Sadari terhadap Keterampilan Sadari pada Ibu di Desa Panggung Rejo Wilayah Kerja Puskesmas Sukoharjo Kabupaten Pringsewu Tahun 2019”. Skripsi. Universitas Muhammadiyah Pringsewu Lampung.

Allenidekani. (2018). "Perilaku Hidup Bersih dan SehatKanker". Depok: Fakultas Ilmu Keperawatan Universitas Indonesia.

Anisah, F. (2012). "Status Karies Gigi dan Faktor-Faktor yang Berhubungan dengan Kesehatan Gigi pada Anak Kelas V di SDN 10 Pancoran Jakarta Selatan Tahun 2012. Skripsi. Universitas Nasional.
Edukasi tentang perawatan mukositis oral menjadi sebesar 19,0294 terjadinya peningkatan sebesar 8,4412. Ada perbedaan sebelum dan sesudah diberikan edukasi tentang perawatan mukositis oral dengan $p$-value $0,000<a(0,05)$.

\section{SARAN}

Diharapkan perawat dapat berperan aktif dalam memberikan edukasi tentang perawatan mukositis oral kepada keluarga pasien yang mempunyai anak dengan kanker. Diharapkan menambah pengetahuan keluarga sehingga dapat menerapkannya kepada pasien dengan adanya peran keluarga terhadap pemeliharaan dan peningkatan kesehatan.

Arumdari, N. P. P., Suyanto. (2017). "Dukungan Keluarga pada Pasien Kanker yang Menjalani Kemoterapi”. Jurnal Universitas Islam Sultan Agung Semarang". ISBN 978-602-1145-69-2 hal 90-91.

Dinamarta, H. A. (2018). “Terapi Okupasi Prakarya terhadap Self-Esteem pada Remaja yang Menjalani Kemoterapi di Ruang Kemuning Atas Rumah Sakit Umum Kabupaten Tangerang". Studi Kasus. Poltekkes Kemenkes Banten.

Donsu, J. D. T. (2017). "Metodologi Penelitian Keperawatan". Yogyakarta: PT Pustaka Baru.

Hermawati, D. (2012). “Pengaruh Edukasi terhadap Pengetahuan dan

Naziyah ${ }^{1}$, Susanti Widiastuti ${ }^{2}$

${ }^{1}$ Dosen Program studi keperawatan Universitas Nasional. Email : naziyah.ozzy@gmail.com

${ }^{2}$ Dosen Program studi keperawatan Universitas Nasional. Email : susanti_widiastuti76@yahoo.com 


$\begin{array}{lr}\text { Rasionalitas } & \begin{array}{r}\text { Penggunaan } \\ \text { Obat }\end{array} \\ \text { Pengumedikasi } \\ \text { Kecamatang di } & \text { Dua Apotek } \\ \text { Depok". Skripsi. } & \text { Cimanggis } \\ \text { Indonesia. } & \end{array}$

Kemenkes R.1. (2013). "Hasil Riset Kesehatan Dasar 2013". Kementerian Kesehatan Republik Indonesia. Jakarta.

Kemenkes R.1. (2018). "Hasil Utama Riskesdas 2018”. Kementerian Kesehatan Republik Indonesia. Jakarta. Diakses pada 10 Oktober 2019 melalui web http://www.depkes.go.id/re sources/download/infoterkini/hasil-riskesdas2018.pdf.

Kurniastuti, A. F. (2015). “Tingkat Pengetahuan tentang Kesehatan Mulut dan Gigi Siswa Kelas IV dan V TA 2014/2015 SD Negeri Grabag Kecamatan Grabag Kabupaten Purworejo Jawa Tengah. Skripsi. Universitas Negeri Yogyakarta.

Larassari, M. (2017). Pengaruh Pemberian Madu dalam Tindakan Oral Care terhadap Mukositis akibat Kemoterapi Fase Konsolidasi pada Anak Akut Leukimia Limfoblastik (ALL) di Ruang Rawat Inap RSU Kabupaten Tangerang. Skripsi. Program Studi Ilmu Keperawatan Universitas Muhammadiyah.

Novrianda, D., Yulastri A. (2017). "Mukositis Oral dan Kualitas Hidup Spesifik-Mukositis Oral pada Anak yang Menjalani Kemoterapi".
13(1). 50-51.

Nurhidayatun. (2012). “Uji Klinis Randomisasi:Pengaruh

Perawatan

Mulut

Penggunaan Madu terhadap

Perubahan Stadium

Mukositis pada Anak Kanker

di RS Kanker Dharmais

Jakarta. Tesis. Universitas Indonesia.

Nursalam. (2013). "Metodologi Penelitian Ilmu Keperawatan". Jakarta : Salemba Medika.

Putri, A. F. (2015). "Dukungan Orangtua yang Memiliki Anak dengan Leukimia Usia 6-12 Tahun RSU Kabupaten Tangerang". Skripsi. Program Stud Ilmu Keperawatan Universitas Islam Negeri Syarif Hidayatullah.

Raharjo, S. (2016). "SPSS Indonesia" diakses pada tanggal 17 Januari 2020 melalui web https: / /www.spssindonesia.co m/2016/08/cara-uji-pairedsample-t-test-dan.html.

Ulfiana, E. (2013). "Pengembangan Palliative Community Health Nursing (PCHN) untuk Meningkatkan Kemandirian Keluarga dalam Merawat Penderita Kanker di Rumah". 8 (2). 309-310.

Utami, K. C. (2017). "Mukositis Oral sebagai Dampak Kemoterapi pada Anak Kanker yang Mendapat Kemoterapi". Skripsi. Program Studi IImu Keperawatan Universitas Udayana.

Naziyah $^{1}$, Susanti Widiastuti ${ }^{2}$

${ }^{1}$ Dosen Program studi keperawatan Universitas Nasional. Email : naziyah.ozzy@gmail.com

${ }^{2}$ Dosen Program studi keperawatan Universitas Nasional. Email : susanti_widiastuti76@yahoo.com 